\title{
The Effect of Surface Machining on the High-Temperature Oxidation of a Single Crystal Ni-Based Superalloy
}

\author{
Nairong Sun, Lanting Zhang*, Zhigang Li, Feng Sun, \\ Xianping Dong and Aidang Shan \\ School of Materials Science and Engineering, Shanghai Jiao Tong University, \\ 800 Dong Chuan Road, Shanghai 200240, People's Republic of China
}

\begin{abstract}
Single crystal samples were subjected to different surface compressive finishing conditions on [001] oriented surfaces. The initial surface residual compressive stresses were determined to be 901,635 and $0 \mathrm{MPa}$, respectively. Isothermal oxidation in ambient atmosphere at 1573 and $1273 \mathrm{~K}$ resulted in a reduction of oxide scale thickness and a change of primary oxides from nickel oxide to alumina on deformed surface. Such result can be attributed to the increased diffusivity of aluminum beneath the deformed surface at high temperatures. [doi:10.2320/matertrans.M2014077]
\end{abstract}

(Received March 3, 2014; Accepted July 7, 2014; Published September 25, 2014)

Keywords: superalloy, surface machining, residual stress, oxidation

\section{Introduction}

Single crystal nickel-based superalloys have been widely used in the gas turbine blades for power plants and advanced aircraft engine blades owing to their superior mechanical strength and high-temperature oxidation resistance. The hightemperature oxidation is one of the critical factors to determine the life-span of these alloys. ${ }^{1)}$

The chemical composition of a nickel-based superalloy is usually complicated, composing of several kinds of solute elements like aluminum, molybdenum, tungsten, chromium tantalum and etc. Some of these solutes such as aluminum and chromium can obviously promote oxidation resistance for the superalloy. Besides chemical effect, it was found that the surface condition of alloy also has an important impact on the structures of oxide films, thereby affecting the oxidation resistances. ${ }^{2-4)}$ Extensive researches ${ }^{5-14)}$ have confirmed that the deformation on alloys can intensely change structures of their oxide films at high temperatures. Most of these studies focused on the oxidation behaviors under different atmosphere or other external conditions for various alloy systems. However, rather limited works have paid attention to the effects of the deformed surface condition on oxidation behaviors for the superalloy at high temperatures (>1000 K). In the present study, we investigated the oxidation behaviors of oriented deformed surfaces of a single crystal nickel-based superalloy at high temperature.

\section{Experimental Procedures}

A second generation Re-containing superalloy (Table 1) was selected in the present investigation. Single crystal rod with [001] orientation were cast by means of crystal selection method in a directionally solidified furnace. Then the obtained single crystal rod was homogenized at temperatures between 1560 and $1590 \mathrm{~K}$ to eliminate the elements segregations between dendrites and inter-dendrites, followed by a two-stage aging at 1373 and $1143 \mathrm{~K}$. Square slices with

*Corresponding author, E-mail: lantingzh@sjtu.edu.cn
Table 1 The nominal composition of researched nickel-based superalloy (mass \%).

\begin{tabular}{cccccccc}
\hline $\mathrm{Ni}$ & $\mathrm{Al}$ & $\mathrm{Cr}$ & $\mathrm{Mo}$ & $\mathrm{W}$ & $\mathrm{Co}$ & $\mathrm{Ta}$ & $\mathrm{Re}$ \\
\hline Bal. & 6.5 & 3.8 & 3.5 & 5.5 & 8.2 & 7.5 & 1.9 \\
\hline
\end{tabular}

dimension of $10 \mathrm{~mm} \times 10 \mathrm{~mm} \times 1.5 \mathrm{~mm}$ were cut from the rod and the cutting faces of the samples were parallel to the [001] direction. In order to induce different surface deformation, the (001) surfaces of the specimens were ground by wheel with a granularity of $100 \mu \mathrm{m}$ or sprayed in a speed of $200 \mathrm{~m} / \mathrm{s}$ by alumina particles with a mean particle size of $50 \mu \mathrm{m}$, respectively. For comparison, another slice was electro-polished to eliminate the surface deformation induced by cutting. Residual surface stresses of the samples were determined by a standard $2 \theta-\sin ^{2} \psi$ method using an X-ray diffractometer (XRD).

For this two-phase $\gamma / \gamma^{\prime}$ superalloy, the $\gamma^{\prime}$ solvus temperature is about $1550 \mathrm{~K}$. When being heated above this temperature, the microstructure of the superalloy changes from $\gamma / \gamma^{\prime}$ duel phases to single $\gamma$ phase. So the isothermal oxidation was conducted at $1573 \mathrm{~K}$ ( $\gamma$ phase) and $1273 \mathrm{~K}$ $(\gamma / \gamma$ phases $)$ in static air for 5 and $100 \mathrm{~h}$, respectively. Cross sectional morphologies of oxides were examined by scanning electron microscopy with energy dispersive spectroscopy analysis (SEM/EDS, JEOL JSM-6460) and their phase constitutions were analyzed by X-ray diffraction method (XRD, Shimadzu XRD-6000).

\section{Results}

The measured residual stresses existed on the surfaces are listed in Table 2. The electro-polished surface is free of residual stress and residual stresses were -901 and $-635 \mathrm{MPa}$ for the ground and sprayed surfaces, respectively. Moreover, the residual stress of the ground surface after exposure at $1573 \mathrm{~K}$ for $0.1 \mathrm{~h}$ still remains $-793 \mathrm{MPa}$, which is a considerable value. 
Table 2 Residual stresses on the surfaces of different samples.

\begin{tabular}{cc}
\hline Surface conditions & Residual stress, $\sigma / \mathrm{MPa}$ \\
\hline Electro-polished & 0 \\
Ground & -901 \\
Sprayed & -635 \\
Ground (after $1573 \mathrm{~K} / 0.1 \mathrm{~h}$ annealing) & -794 \\
\hline
\end{tabular}

Figure 1 shows the cross-section morphologies of surfaces exposed at $1573 \mathrm{~K}$ and $1273 \mathrm{~K}$ respectively.

After exposure at $1573 \mathrm{~K}$ for $5 \mathrm{~h}$, it is shown that the thickness of the formed oxide scale which contains several intermittent layers on electro-polished surface is about $80 \mu \mathrm{m}$ (Fig. 1(a)). The scale formed on electro-polished surface after $1273 \mathrm{~K} / 100 \mathrm{~h}$ exposure was composed of three layers: a loose outer layer containing cracks, a compact inner layer and a thin middle one (Fig. 1(b)). The total thickness is measured to be about $8 \mu \mathrm{m}$.

The oxide scales formed on the deformed surfaces are quite different. A three-layer oxide was found on the sprayed surface after $1573 \mathrm{~K} / 5 \mathrm{~h}$ exposure (Fig. 1(c)). After $1273 \mathrm{~K} /$ $100 \mathrm{~h}$ exposure, the sprayed surface was covered by a single layer of oxide about $4 \mu \mathrm{m}$ and some needle-like precipitates were found under the scale (Fig. 1(d)). A $\gamma$ free layer which was caused by the depletion of aluminum can be seen beneath the oxide scale. ${ }^{15,16)}$

The oxide scale on the ground surface was thin $(2.5-3 \mu \mathrm{m})$ and compact after $1573 \mathrm{~K} / 5 \mathrm{~h}$ exposure (Fig. 1(e)). Similar scenario was found for the ground samples exposed to $1273 \mathrm{~K}$ (Fig. 1(f)), besides the scale was thinner, almost no obvious $\gamma$ free layer was found. Figure $1(\mathrm{~g})$ illustrates that an intact oxide layer has also formed on the ground surface shortly after exposure at $1573 \mathrm{~K}$ for $0.1 \mathrm{~h}$ only.

The isothermal oxidation kinetic at $1273 \mathrm{~K}$ for $100 \mathrm{~h}$ of each sample showed a parabolic time dependence of growth rate. It can be described by examining the growth-time constants $n$ :

$$
(\Delta m / A)=k t^{n}+C
$$

where $\Delta m$ is the change in mass, $A$ is the sample surface area, $k$ is the oxidation rate constant, $t$ is the exposure time, and $C$ is a constant. The growth-rate time constant $n$ can be calculated from a slope of a log-log plot for taking logarithms of both sides of eq. (1). Figure 2 shows that the ground surface possesses a lowest $n$ value while the electropolished surfaces got the highest value.

The detailed compositions of different kinds of oxide layers formed on the samples after exposure at 1573 and $1273 \mathrm{~K}$ were determined by EDS (Table 3, Fig. 3) and XRD (Fig. 4) respectively.

After oxidation at $1573 \mathrm{~K}$, it can be concluded that the oxide scale on electro-polished surface is mainly composed of nickel oxide $(\mathrm{NiO})$ mixed with a few other oxides (such as tantalum oxide $\left(\mathrm{TaO}_{2}\right)$, spinel $\left(\mathrm{NiAl}_{2} \mathrm{O}_{4}\right)$, molybdenum oxide $\left(\mathrm{MoO}_{3}\right)$, etc. $)$ and some alumina $\left(\mathrm{Al}_{2} \mathrm{O}_{3}\right)$. On sprayed surface, the outer and inner oxide layers are alumina while the middle layer contains spinel. For the ground surface where a single intact layer of oxide is found, it is composed of alumina.
After oxidation at $1273 \mathrm{~K}$, the loose outer layer of the scale on the electro-polished surface is nickel oxide, and the compact inner layer is alumina, some chromium slightly enrich in the middle of the scale (a line scan map in Fig. 3). The monolayer oxides formed on both sprayed and ground surfaces exposed to $1273 \mathrm{~K}$ are alumina.

\section{Discussion}

It is obvious that the surface condition can dramatically change the oxide structure on the surface of the single crystal nickel based superalloy. The remarkable differences between the oxide structures formed on electro-polished and deformed surfaces can be attributed to the results of different selective oxidation processes. At both 1573 and $1273 \mathrm{~K}$, the oxide products changes from primary nickel oxide on polished surface to preferential alumina on deformed surface. The $\mathrm{Al}_{2} \mathrm{O}_{3}$ layer is more ductile and compact than the $\mathrm{NiO}$ layer which cannot prevent further oxidation of matrix at high temperature. ${ }^{17-21)}$

The critical concentration of an element (Al) is needed for the formation of a continuous preferential external oxide layer. According to the theory of Wagner, ${ }^{22)}$ the critical solution concentration could be expressed as:

$$
N_{\mathrm{Al}}^{*}=\left(\frac{\pi g^{*} N_{\mathrm{o}}^{\mathrm{s}} N_{\mathrm{o}} D_{\mathrm{o}} V_{\mathrm{m}}}{3 D_{\mathrm{Al}} V_{\mathrm{Al}_{2} \mathrm{O}_{3}}}\right)^{1 / 2}
$$

where $g^{*}$ is a factor determined by the volume fraction of oxide, $V_{\mathrm{m}}$ and $V_{\mathrm{Al} 2 \mathrm{O} 3}$ are the molar volumes of the alloy and alumina respectively, $N_{0}^{\mathrm{s}} N_{\mathrm{o}}$ is the concentration of oxygen at the surface, $D_{\mathrm{o}}$ and $D_{\mathrm{Al}}$ are the diffusivities of oxygen and aluminum in matrix. According to the above formula, the critical $\mathrm{Al}$ content required for the preferential formation of an external alumina can decrease with the increase in diffusivity of the solute (Al) in this alloy.

The deformation induced oxidation has been well known and extensively studied on other alloys. ${ }^{23-25)}$ It is reasonable that the structure of surface of deformed sample is much different from the electro-polished one, and this has a large effect on the diffusivity of solute elements beneath the surface.

Although the microstructures of surfaces of machined samples are highly deformed, no obvious elements' concentrations were found beneath the surfaces just after deformation (Fig. 5). But these deformed surfaces contain lots of defects such as vacancies, dislocations, and their lattices are also distorted as well. ${ }^{26)}$ These defects can give rise to the broadening of XRD diffraction profile of the surfaces. Figure 6 compares the (002) diffraction peak lines of the three surfaces with various conditions respectively. It is obvious that the diffraction profile of ground surface is most seriously broadened, while the profile width of electropolished surface is narrowest and sharpest (note that a small peak at $50.75 \mathrm{deg}$ of electro-polished surface confirms the part diffractive intensity of $\gamma$ matrix due to the elements segregation of the highly solute superalloy). ${ }^{23)}$ Furthermore, the obvious offset of the diffraction peak of ground sample caused by the higher residual stress on its surface. Considering no grain boundaries existed, it is evident that both the two deformed surfaces have vast defects compared 

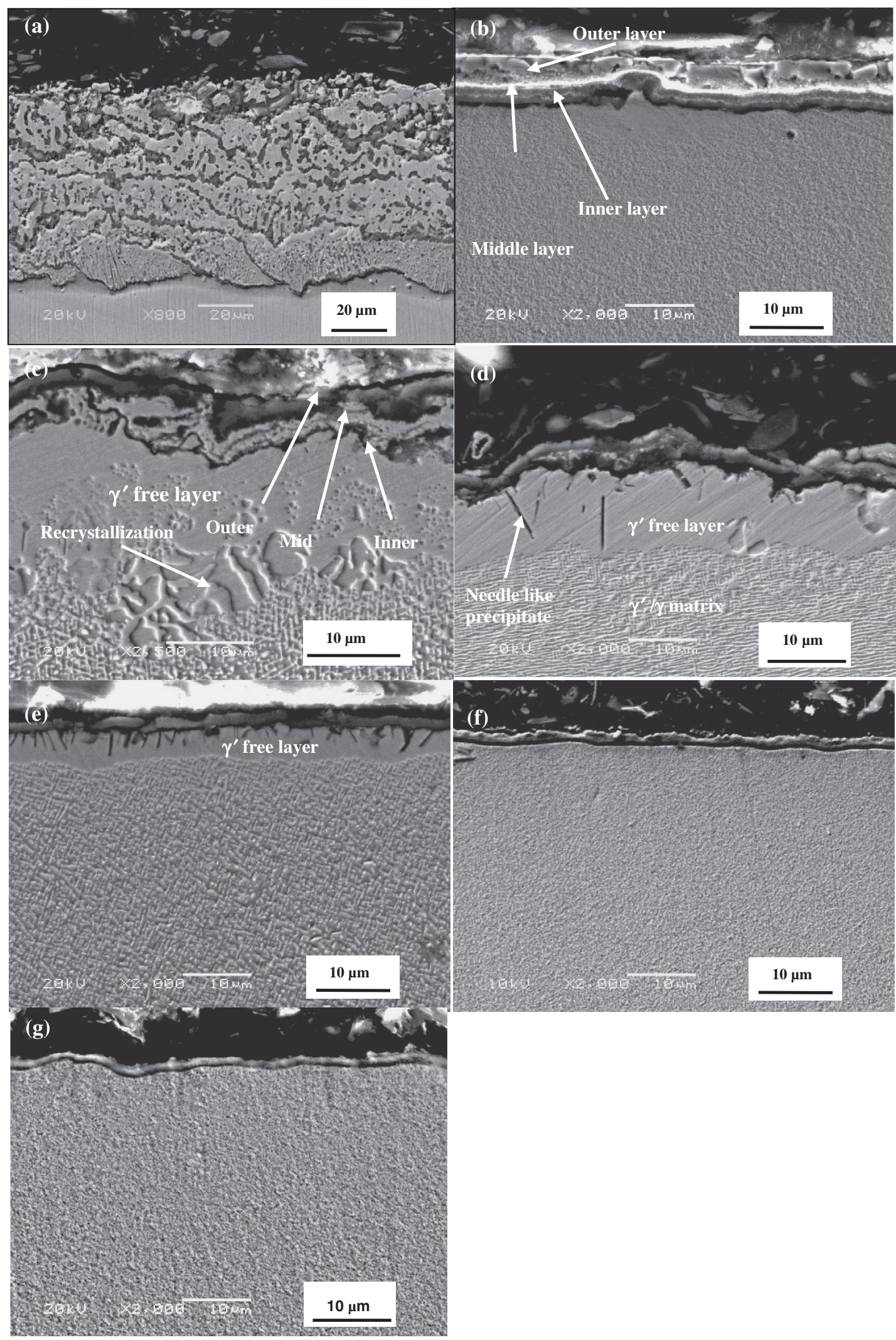

Fig. 1 SEM images of cross-sections of alloy samples oxidized at different temperatures: (a) electro-polished surface at $1573 \mathrm{~K} / 5 \mathrm{~h}$; (b) electro-polished surface at $1273 \mathrm{~K} / 100 \mathrm{~h}$; (c) sprayed surface at $1573 \mathrm{~K} / 5 \mathrm{~h}$; (d) sprayed surface at $1273 \mathrm{~K} / 100 \mathrm{~h}$; (e) ground surface at $1573 \mathrm{~K} / 5 \mathrm{~h}$; (f) ground surface at $1273 \mathrm{~K} / 100 \mathrm{~h}$. (g) ground surface at $1573 \mathrm{~K}$ for a short $0.1 \mathrm{~h}$ exposure.

to the electro-polished one. By short-circuited diffusion of aluminum that induced by these defects, the concentration of aluminum beneath the deformed surface can increase at high temperature. In addition, the existed compressive residual stress can also affect the diffusivity of solute element in an alloy, and some researches have been made on this respect. $^{27-30)}$ J.N.F. Sage ${ }^{31)}$ considered that compressive stress on a surface can create a volume strain of the matrix 

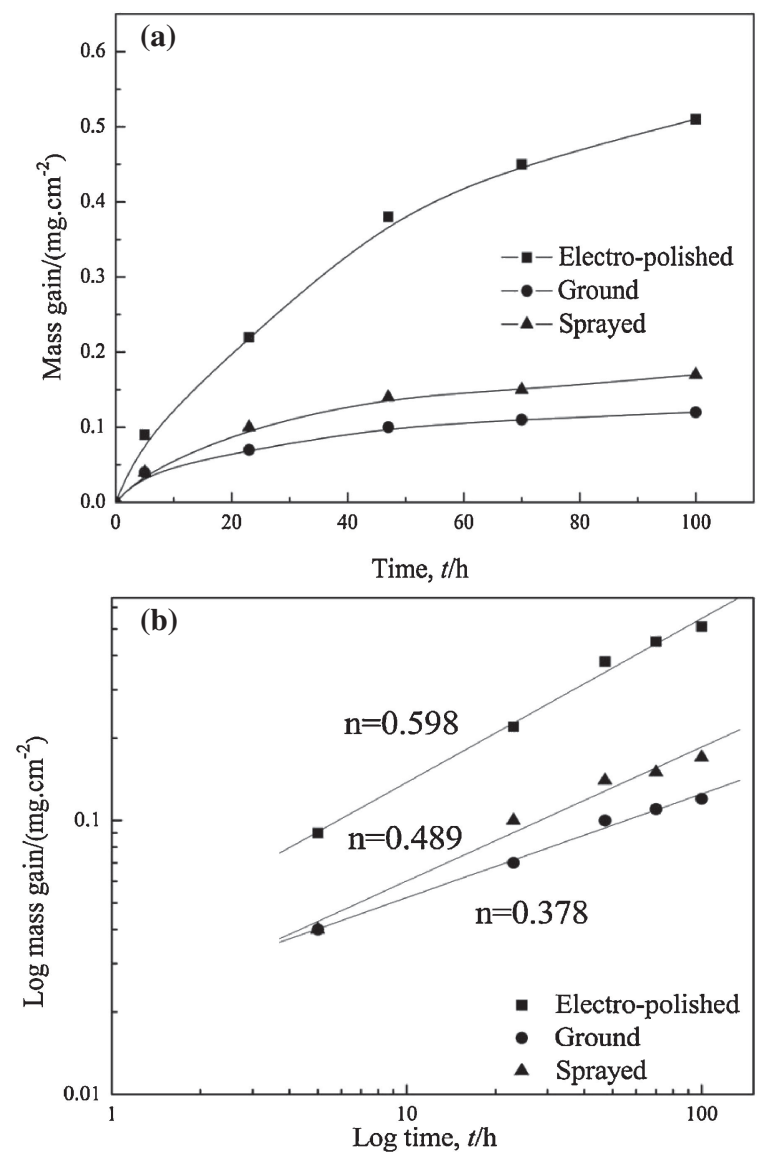

Fig. 2 Isothermal oxidation kinetics curves of samples with different surface conditions at $1273 \mathrm{~K}$ (a) and their oxidation rate constants (b).

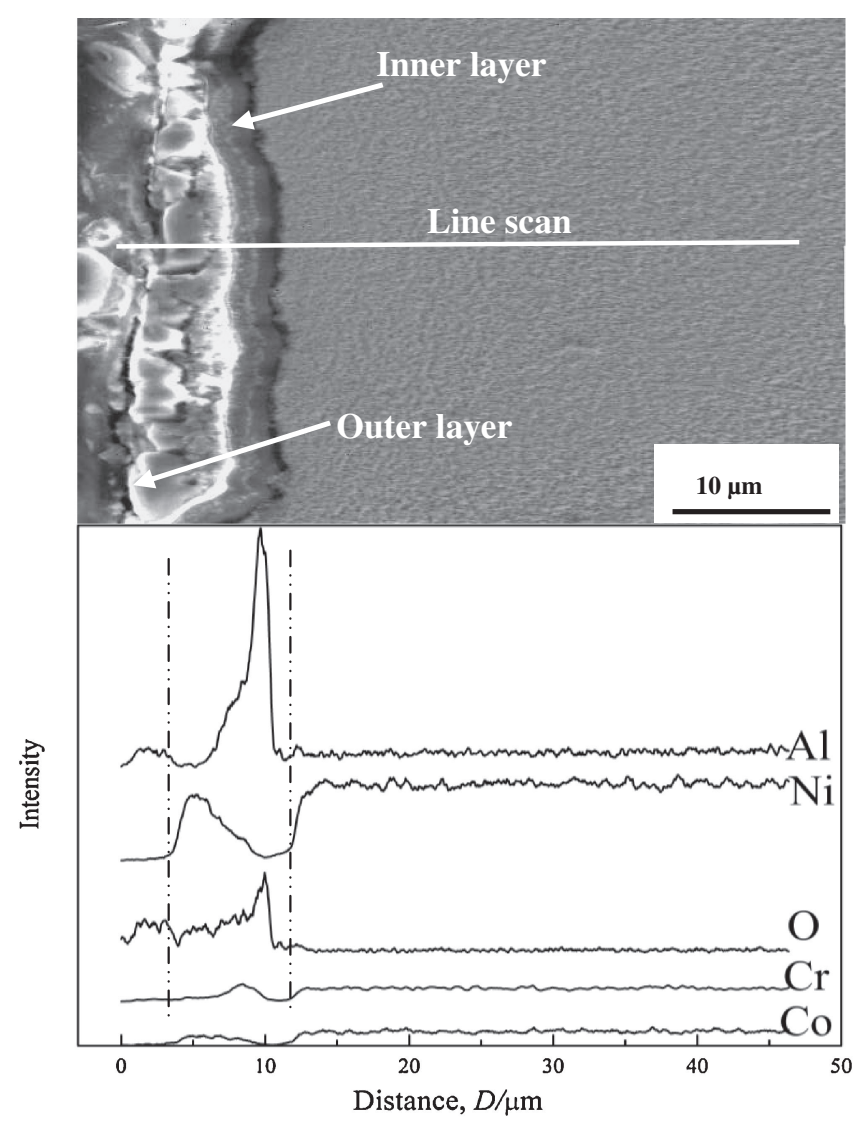

Fig. 3 Line-scan spectrum of the elements distribution for the electropolished sample exposed to $1273 \mathrm{~K}$ for $100 \mathrm{~h}$.

Table 3 Compositions (at\%) of oxide layers for samples after oxidation at $1573 \mathrm{~K}$ and $1273 \mathrm{~K}$ determined by EDS.

\begin{tabular}{|c|c|c|c|c|c|c|c|c|c|c|}
\hline Temperature, $T / \mathrm{K}$ & Samples & Oxide & $\mathrm{O}$ & $\mathrm{Al}$ & $\mathrm{Ni}$ & $\mathrm{Co}$ & $\mathrm{Cr}$ & $\mathrm{Ta}$ & W & Mo \\
\hline \multirow{5}{*}{1573} & Electro-polished & Light gray & 42.5 & 3.9 & 44.4 & 2.7 & 1.7 & 1.6 & 0.3 & 3.1 \\
\hline & \multirow{3}{*}{ Sprayed } & Deep gray & 50.8 & 30.7 & 13.8 & - & 4.3 & - & 0.1 & 0.4 \\
\hline & & Intermediate & 55.4 & 26.3 & 15.2 & 2.6 & 0.5 & - & - & - \\
\hline & & Inner & 50.8 & 42.3 & 5.2 & 1.7 & - & - & - & - \\
\hline & Ground & Monolayer & 56.8 & 42.3 & 0.9 & - & - & - & - & - \\
\hline \multirow{4}{*}{1273} & \multirow[t]{2}{*}{ Electro-polished } & Outer & 50.6 & 0.3 & 45.5 & 3.3 & 0.2 & - & - & - \\
\hline & & Inner & 53.8 & 43.8 & 0.7 & 1.2 & 0.6 & - & - & - \\
\hline & Sprayed & Monolayer & 56.3 & 42.9 & 0.8 & - & - & - & - & - \\
\hline & Ground & Monolayer & 57.9 & 41.7 & 0.3 & - & - & - & - & - \\
\hline
\end{tabular}

and that can offer excess activation energy for accelerating solutes' diffusions. On the other hand, for the deformed samples exposed at $1573 \mathrm{~K}$, some recrystallized grains appeared beneath the surface (Fig. 1 (c)). The grain boundaries of these recrystallized grains can also give an extra enhancement to the diffusions of solutes as well. All the above reasons decrease the critical $\mathrm{Al}$ content needed for the formation of a continuous external alumina layer on a deformed surface.

A schematic sketch of oxidation progress is shown in Fig. 7. On the electro-polished surface, a preferable nickel oxide layer is reasonable at the early stage of exposure at both temperatures (Fig. 7 (a)). At $1273 \mathrm{~K}$, the growing preferential friable nickel oxide layer cannot prevent the inward diffusion of oxygen, which would react with other atoms (chromium, aluminum, etc.) beneath the nickel oxide layer and caused a chromium-rich middle oxide layer. Since the higher content of aluminum in this alloy gets a higher oxygen affinity than other solutes, the alumina particle can grow close to the matrix. Then the inner alumina layer gradually provides a barrier to the inward diffusion of oxygen as a consequence. Thus, the classical three-layer oxide was established on the electro-polished surface during early transient oxidation stage. After that, the scale growth is slowed down and a stable structure of the alumina scale is formed at $1273 \mathrm{~K}$ as shown in Figs. 1(b) and 7 (c). When it is 

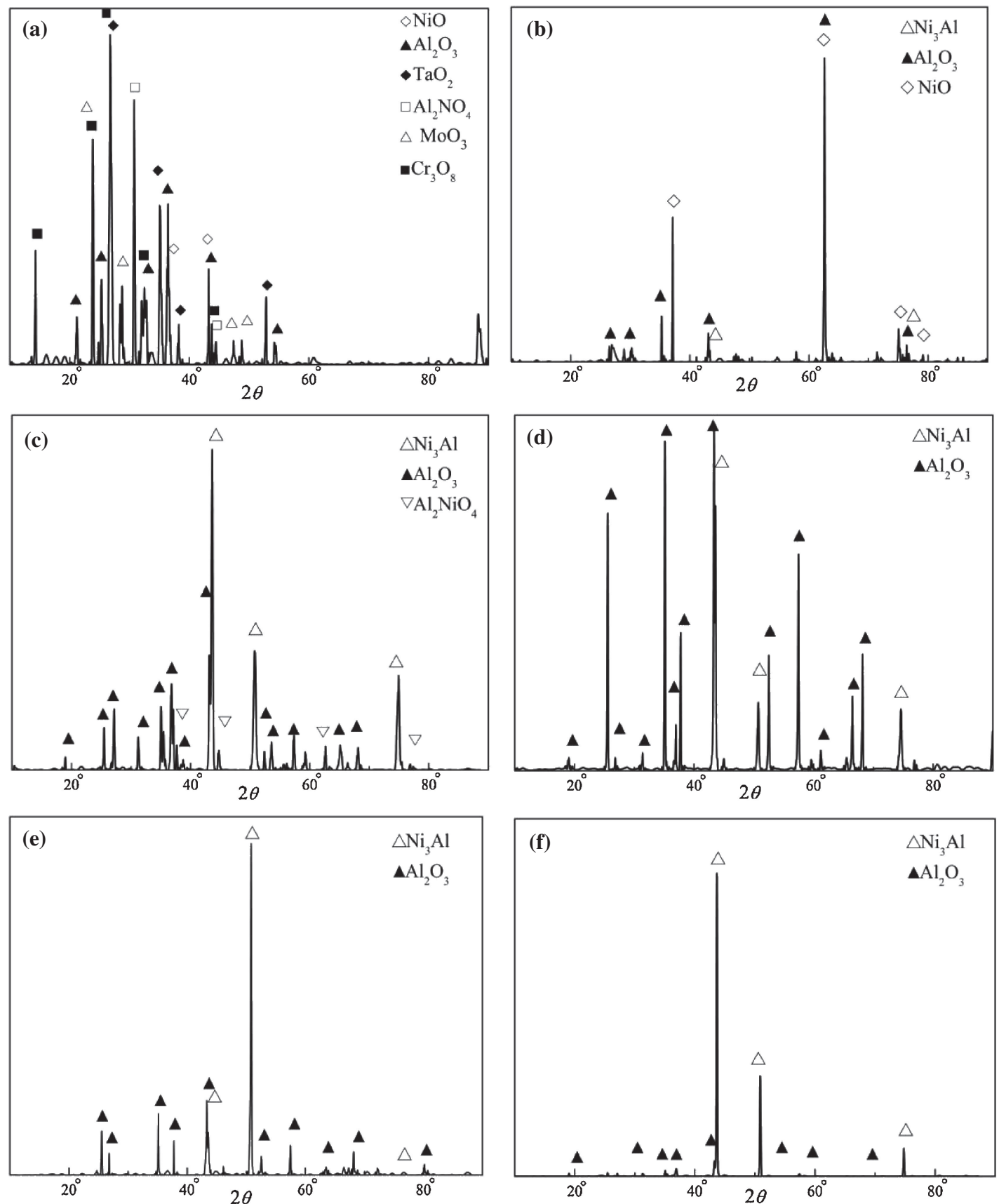

Fig. 4 XRD patterns of the samples oxidized at $1573 \mathrm{~K} / 5 \mathrm{~h}$ and $1273 \mathrm{~K} / 100 \mathrm{~h}$ : (a) electro-polished surface at $1573 \mathrm{~K}$; (b) electro-polished surface at $1273 \mathrm{~K}$; (c) sprayed surface at $1573 \mathrm{~K}$; (d) sprayed surface at $1273 \mathrm{~K}$; (e) ground surface at $1573 \mathrm{~K}$; (f) ground surface at $1273 \mathrm{~K}$.

exposed at $1573 \mathrm{~K}$, both the diffusion rates of oxygen and aluminum can increase, the initial alternate growths of $\mathrm{NiO}$ and $\mathrm{Al}_{2} \mathrm{O}_{3}$ are both dominant. It results in an oxide scale delaminated with alumina and nickel oxide alternately. Due to the discrete alumina formation, the whole oxide scale is loose and provides poor resistance to further oxygen diffusion. Ultimately the inward continuous oxidation creates a thick and multilayer oxide structure on the electro-polished surface as shown in Figs. 1(a) and Fig. 7(d).

The behaviors of oxidation on the ground surfaces are similar at 1573 and $1273 \mathrm{~K}$ (Figs. 7 (b) and (e)). The increased diffusion flux of $\mathrm{Al}$ beneath the deformed surface offers driving forces for the preferential formations of alumina scales at both temperatures. Thus the alumina layers can form completely, provide the best oxidation-resistance and no other oxides appears beneath the layers with extend of exposure time. Figure $1(\mathrm{~g})$ also indicates that the protective preferential alumina layer has formed on the ground surface only after a short period of time at $1573 \mathrm{~K}$.

As to the sprayed surfaces, external continuous alumina layers can also be formed after exposure at 1573 and $1273 \mathrm{~K}$ (Figs. 1(c) and (d)). Although the preferential alumina coated on sprayed surfaces, some inner oxidation can still happen. An inner strap with small amounts of spinel detected by $\mathrm{X}$-ray formed beneath the alumina scale on the sprayed surface exposed at $1573 \mathrm{~K}$ (Figs. 4(c)). Some needle-liked inner precipitates can develop under the external scale at $1273 \mathrm{~K}$. It is evident that the alumina oxide scales on the 

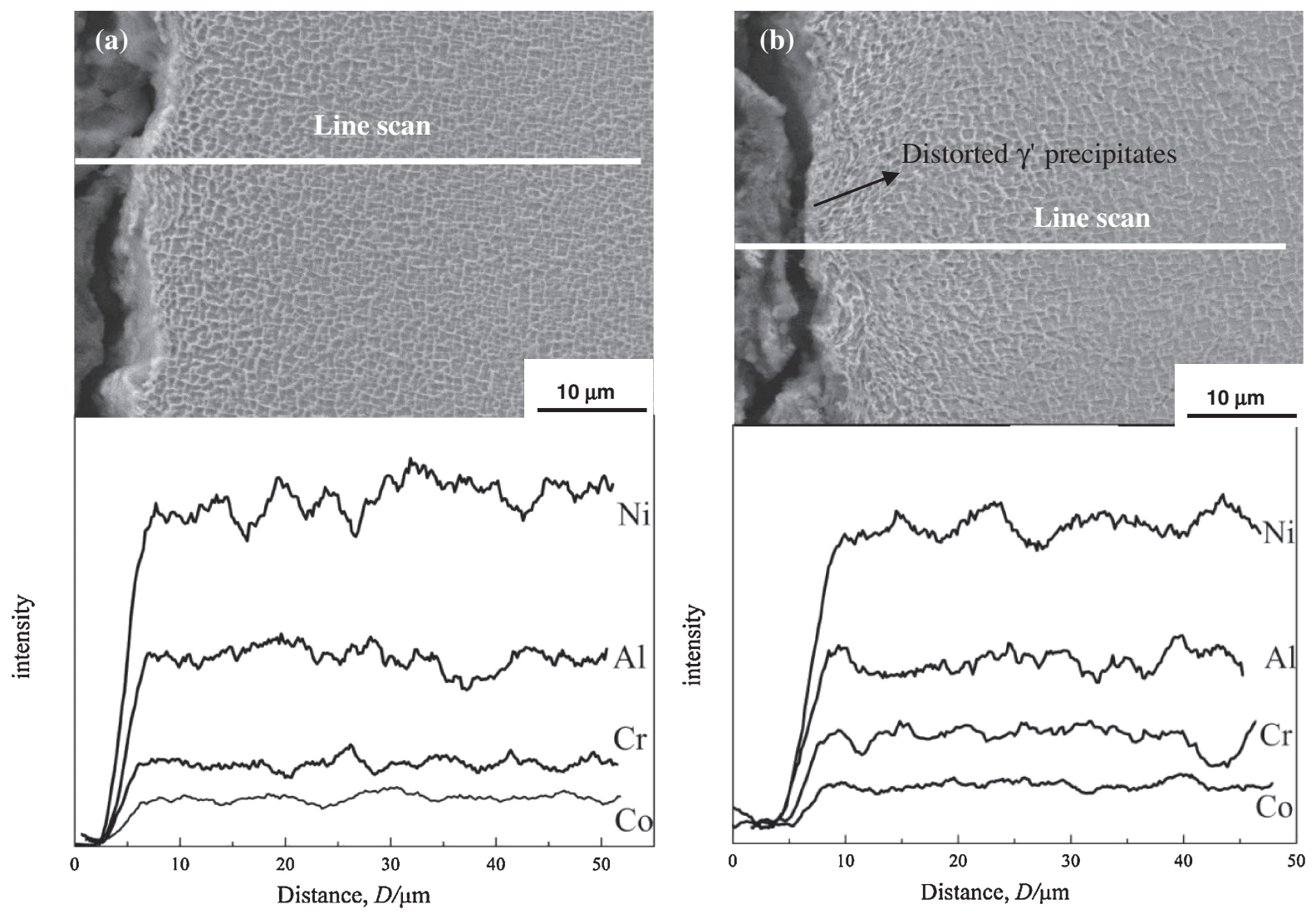

Fig. 5 Respective line-scan spectrum of the elements distribution for the samples just after sprayed (a) and ground (b).

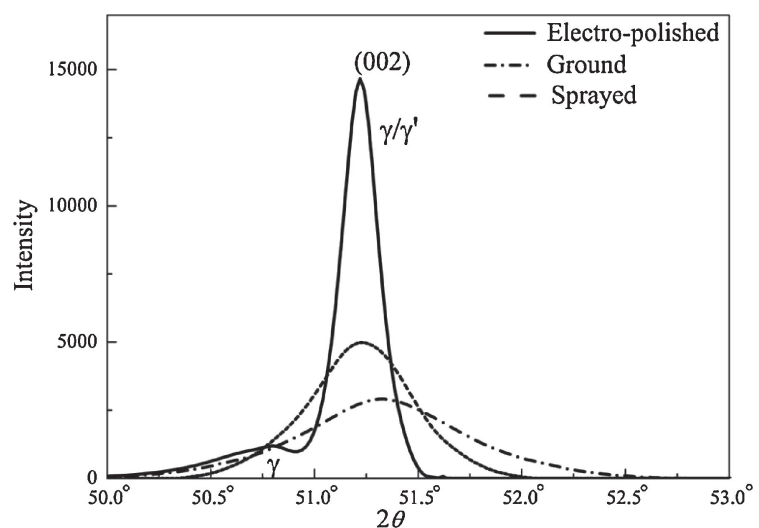

Fig. 6 The (002) diffraction profiles for the electro-polished, ground and sprayed samples respectively.

sprayed samples are not stable enough for completely preventing the penetration of oxygen into the matrix. This indicates that the lower diffusivity of $\mathrm{Al}$ induced by a lower deformation beneath the sprayed surface compared to the ground surface.

Furthermore, the depth of the alumina scale at $1573 \mathrm{~K}$ was thicker than that of $1273 \mathrm{~K}$ for both electro-polished and machined samples. This might be due to two reasons: First, both oxygen and aluminum can diffuse faster in the oxide scale at higher temperature and it results in a further oxidation on a surface. Second, $\gamma$ precipitates $\left(\mathrm{Ni}_{3} \mathrm{Al}\right)$ were dissolved in the matrix for this $\gamma^{\prime}$ strengthened alloy at $1573 \mathrm{~K}$, it gives rise to obvious concentration augments of aluminum in the matrix and favors the acceleration of alumina formation.

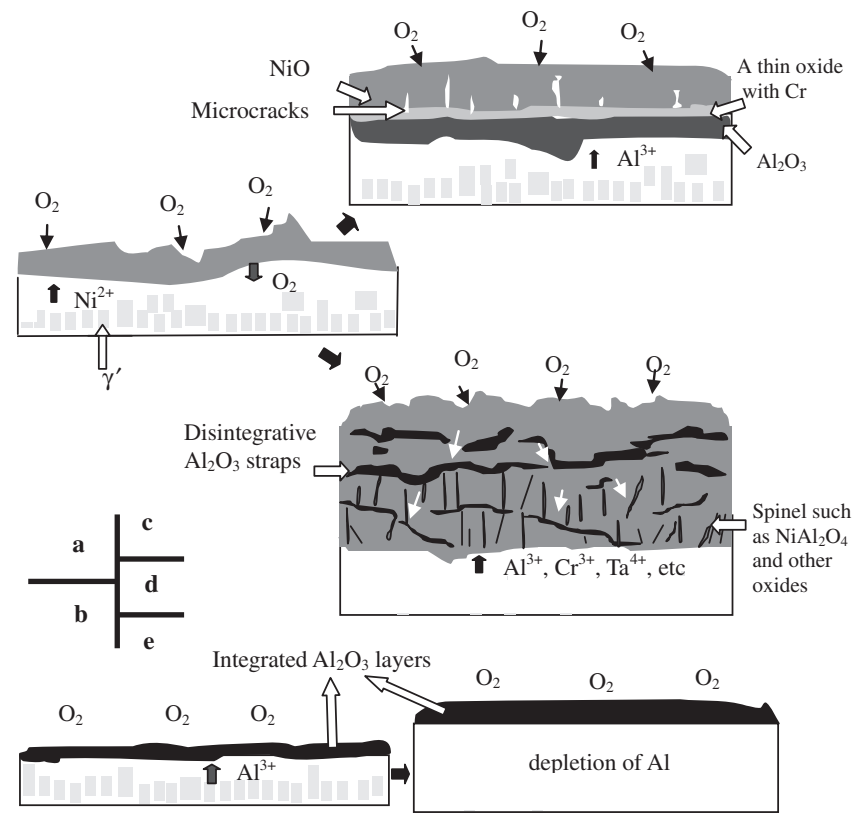

Fig. 7 Schematic sketch for formation mechanism of scale and subscale on the (001) surfaces of the single crystal superalloy: (a) oxidation at early stage on electro-polished surface; (b) oxidation at early stage on ground surface; (c) oxidation after $100 \mathrm{~h}$ at $1273 \mathrm{~K}$ on electro-polished surface; (d) oxidation after $5 \mathrm{~h}$ at $1573 \mathrm{~K}$ on electro-polished surface; (e) oxidation after $5 \mathrm{~h}$ at $1573 \mathrm{~K}$ on ground surface.

The deformation on the surface was discussed here to explain the notable difference of oxide structures formed on the oriented surfaces of a single crystal superalloy, but some factors have not been taken into account for simplifying this 
research. It is well known that the initial surface roughness of matrix could aggravate the oxidation of metals. ${ }^{31-34)}$ But according to the results of experiments on this superalloy, the deformed surfaces exhibit much better oxide-resistances. Thus, the various initial surface roughness induced by different machining may also have positive impact on the preferred formation of alumina which offers better oxygenresistance. Further work should be undertaken for in-depth understanding.

\section{Conclusion}

The surface machining can dramatically alter the oxidation behavior on [001] surface of a nickel-based single crystal superalloy at both 1573 and $1273 \mathrm{~K}$. The change of external oxides from nickel oxide on electro-polished surface to alumina on machined surface is the result of the promoted diffusivity of aluminum beneath the deformed surface. Both the sprayed and ground samples formed compact alumina oxide layers and exhibited much better oxidation-resistant properties compared to the electro-polished sample at both 1573 and $1273 \mathrm{~K}$.

\section{Acknowledgements}

This work is supported by the Science and Technology Committee of Shanghai Municipality (Grant No. 08dj1400402 and 12JC1405000).

\section{REFERENCES}

1) L. Huang, X. F. Sun, H. R. Guan and Z. Q. Hu: Surf. Coat. Tech. 200 (2006) 6863-6870.

2) A. Akhtar, M. S. Hook and R. C. Reed: Metall. Mater. Trans. A 36 (2005) 3001-3017.

3) C. M. Younes, G. C. Allen and J. A. Nickelcholson: Corros. Eng. Sci. Technol. 42 (2007) 80-88.

4) A. Raffaitin, D. Monceau, E. Andrieu and F. Crabos: Acta Mater. 54 (2006) 4473-4487.
5) M. Schütze: Oxid. Met. 25 (1986) 409-421.

6) G. Calvarin-Amiri, R. Molins and A. M. Huntz: Oxid. Met. 53 (2000) 399-426.

7) G. Calvarin-Amiri, A. M. Huntz and R. Molins: Mater. High Temp. 18 (2001) 91-99.

8) M. M. Nagl and W. T. Evans: J. Mater. Sci. 28 (1993) 6247-6260.

9) C. H. Zhou, H. T. Ma and L. Wang: Oxid. Met. 70 (2008) 287-294.

10) G. B. Gibbs and R. Hales: Corros. Sci. 17 (1977) 487-507.

11) P. Kofstad: Oxid. Met. 24 (1985) 265-276.

12) A. Takei and K. Nii: Trans. Jpn. Inst. Met. 25 (1984) 561-568.

13) Y. H. Qian, M. S. Li and Y. M. Zhang: Acta Metall. Sin. 39 (2003) 989-994.

14) C. Ostwald and H. J. Grabke: Corros. Sci. 46 (2004) 1113-1127.

15) B. H. Kear, F. S. Pettit, D. E. Fornwalt and L. P. Lemaire: Oxid. Met. 3 (1971) 557-569.

16) C. T. Liu, J. Ma and X. F. Sun: J. Alloy. Compd. 491 (2010) 522-526.

17) D. M. Lipkin, D. R. Clarke, M. Hollatz, M. Bobeth and W. Pompe: Corros. Sci. 39 (1997) 231-242.

18) M. Schütze: Mater. Sci. Tech. 4 (1988) 407-414.

19) J. Robertson and M. I. Manning: Mater. Sci. Tech. 6 (1990) 81-92.

20) P. Hancock and J. R. Nicholls: Mater. Sci. Tech. 4 (1988) 398-406.

21) C. Jin: Corros. Sci. Prot. Tech. 6 (1994) 63-66.

22) C. Wagner: ElectrKhem. 63 (1959) 772-790.

23) U. Brückner, A. Epishin, T. Link and K. Dressel: Mater. Sci. Eng., A 247 (1998) 23-31.

24) A. R. Paul, K. N. G. Kaimal, M. C. Naik and S. R. Dharwadkar: J. Nucl. Mater. 217 (1994) 75-81.

25) E. Chassagneux, M. Soustelle and G. Thomas: Oxid. Met. 27 (1987) 301-314.

26) X. G. Li, M. Fu and J. W. He: Mater. Sci. Tech. 12 (2004) 253-257.

27) O. Stephansson: Tectonophysics 22 (1974) 233-251.

28) A. M. Simon and Z. J. Grzywna: Acta Metall Mater. 40 (1992) 34653473 .

29) Y. M. Sheu, S. J. Yang, C. C. Wang, C. S. Chang, L. P. Huang, T. Y. Huang and M. J. Chen: IEEE T Electron Dev. 52 (2005) 30-38.

30) N. E. B. Cowern, P. C. Zlam, P. C. van der Sluis, D. J. Gravesteijn and W. B. Boer: Phys. Rev. Lett. 72 (1994) 2585-2588.

31) J. N. F. Sage: Doctral Thesis, (Harvard University, Cambridge, Massachusetts, 2005) pp. 20-21.

32) D. Caplan, M. J. Graham and M. Cohen: J. ElectrKhem. 119 (1972) 1205-1215.

33) M. J. Graham, G. I. Sproule, D. Caplan and M. Cohen: J. ElectrKhem. SK 119 (1972) 883-887.

34) S. Uran, B. Veal, M. Grimsditch, J. Pearson and A. Berger: Oxid. Met. 54 (2000) 73-85. 